\title{
Relato de Experiência: teoria e prática na formação de parcerias para o Projeto CosturaViva
}

\author{
Experience Report: theory and practice in forming \\ partnerships for the CosturaViva Project
}

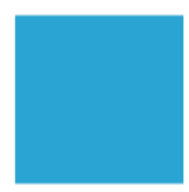
em Foco
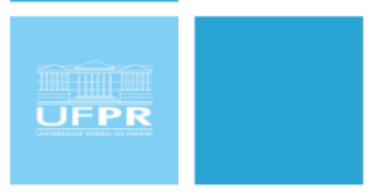

ISSN $2358-7180$

\section{Cristiane Perin de Oliveira ${ }^{1}$, Elenir Carmen Morgenstern ${ }^{2}$, Luiz Melo Romão ${ }^{3}$, Rita de Cássia Rothbarth Lorenzi ${ }^{4}$}

\begin{abstract}
RESUMO
Este trabalho visa relatar as atividades desenvolvidas junto ao projeto de extensão intitulado "CosturaViva" na construção de um plano estratégico para prospecção de parcerias. Apresenta o percurso metodológico englobando aprofundamento teórico, pesquisa documental, estudo de campo, aplicação de ferramentas do campo do design e adaptação do Balanced Scorecard - BSC para o projeto. A partir da aplicação da metodologia proposta, foram produzidos o mapa de agentes do projeto, as diretrizes para formação de parcerias e o plano estratégico com as parcerias prospectadas. O processo mostrou-se efetivo no seu objetivo de prospectar parcerias diversas. As possibilidades vislumbradas, se concretizadas, tendem a contribuir significativamente para a manutenção financeira do projeto e para a expansão do número de participantes, potencializando a ressocialização das reeducandas do Presídio Regional de Joinville/SC.
\end{abstract}

Palavras-chave: Sistema prisional. Parcerias. Ressocialização.

\section{ABSTRACT}

This work aims to report the activities developed at the extension project entitled "CosturaViva" in the construction of a strategic plan for prospecting partnerships. It presents the methodological path encompassing theoretical deepening, documentary research, field study, application of design tools and adaptation of the Balanced Scorecard - BSC for the project. From the application of the proposed methodology, the map of project agents, the guidelines for forming partnerships and the strategic plan with prospected partnerships were produced. The process proved to be effective in its goal of exploring diverse partnerships. The envisaged possibilities, if realized, tend to contribute significantly to the financial maintenance of the project and to the expansion of the number of participants, potentiating the resocialization of the women of the Regional Prison of Joinville/SC.

Keywords: Prison system. Partnerships. Resocialization.

\footnotetext{
${ }^{1}$ Mestranda em Design. Universidade da Região de Joinville (Univille), Joinville, Santa Catarina, Brasil. E-mail: crisperindeoliveira@gmail.com. Orcid: https://orcid.org/0000-0002-4537-794X

${ }^{2}$ Doutora em Design. Pontifícia Universidade Católica do Rio de Janeiro (PUC-Rio), Rio de Janeiro, Rio de Janeiro, Brasil. E-mail: elenir.m@gmail.com. Orcid: https://orcid.org/0000-0002-6384-6068

${ }^{3}$ Doutor em Informática. Pontifícia Universidade Católica do Paraná (PUCPR), Curitiba, Paraná, Brasil. E-mail: luizmromao@gmail.com. Orcid: https://orcid.org/0000-0002-1127-9858

${ }^{4}$ Mestre em Design. Universidade da Região de Joinville (Univille), Joinville, Santa Catarina, Brasil. E-mail: rita.lorenzi@gmail.com.
} 


\section{INTRODUÇÃO}

O CosturaViva é um Projeto Integrado de Ensino-Pesquisa-Extensão da Universidade da Região de Joinville - Univille que tem por objetivo promover pesquisa e desenvolvimento de conhecimentos técnico-científicos, em moda e empreendedorismo, aplicados à capacitação profissional e ressocialização de reeducandas do Presídio Regional de Joinville/SC.

O núcleo estruturante da capacitação encontra-se nos conhecimentos relacionados a produção de moda (por meio da modelagem e costura, em especial, acrescentando-se técnicas de estamparia e serigrafia, para beneficiamento e valorização de tecidos reaproveitados, e saberes referentes a projeto de produto e gráfico) e ao empreendedorismo (por meio do desenvolvimento do perfil empreendedor e de ferramentas de gestão).

São elementos fundamentais do Projeto CosturaViva a integração entre ensino, pesquisa e extensão ${ }^{1}$, a interdisciplinaridade - uma vez que a variedade dos campos do saber é fundamental para as produções híbridas, que integram artesanato e design - e a integração entre teoria e prática, evidenciada na relação estabelecida entre conhecimento acadêmico e os saberes próprios do grupo de mulheres participantes.

Iniciada em 2018, a execução do projeto se mostrou bastante desafiadora, tanto em função da complexidade intrínseca ao contexto do sistema prisional ${ }^{2}$ quanto em razão das limitações orçamentárias do projeto. Reflexo deste cenário é o número de participantes: a proposta inicial tencionava atender a 20 detentas do presídio; entretanto, as aulas com maior quórum contavam com sete alunas.

Buscando superar tais desafios, a formação de parcerias se mostrou mecanismo relevante, pois amplia as possibilidades de captação de insumos, gera potencial de comercialização e promove o trabalho das reeducandas junto à sociedade em geral.

Assim, entre os meses de maio/2019 e janeiro/2020 foram realizadas diversas atividades com o intuito de se estruturar a formação de parcerias para o Projeto CosturaViva.

O presente relato de experiência apresenta o percurso realizado para a construção de um plano estratégico que objetiva o estabelecimento de parcerias que possam auxiliar na manutenção do projeto e expansão do número de participantes e, assim, potencializar a ressocialização das reeducandas do Presídio Regional de Joinville/SC. 


\section{METODOLOGIA}

A fim de colher subsídios que pudessem fomentar a criação de propostas de formação de parcerias para o Projeto CosturaViva, realizou-se aprofundamento teórico, pesquisa documental, estudo de campo, aplicação de ferramentas do campo do design e, por fim, o desenvolvimento de plano estratégico para prospecção ${ }^{3}$ de parcerias.

\section{Aprofundamento teórico}

Foram realizados estudos dos autores Pierre Bourdieu, Janet Wolff, Alberto Cipiniuk e Fritjof Capra, buscando maior compreensão da abordagem sistêmica e do design como produto social. Também foram consultadas publicações relacionadas a projetos sociais, sustentabilidade, capacitação profissional, sistema prisional e planejamento estratégico.

\section{Pesquisa documental}

Foi realizado estudo do escopo do Projeto CosturaViva apresentado na Chamada de Projetos Integrados de Ensino-Pesquisa-Extensão, objeto do Edital Univille 01/18/PROEN/PRPPG/PROEX. Destaque-se que não houve acesso a informações financeiras e/ou restritas às comissões vinculadas ao referido edital.

\section{Estudo de campo}

O estudo de campo englobou entrevistas e interações com pessoas vinculadas direta ou indiretamente ao projeto. Os encontros tinham por objetivo compreender o processo produtivo e a cadeia de valor a partir da visão dos interlocutores, identificar agentes ${ }^{4}$ do projeto e vislumbrar possibilidades de parcerias.

Nesta etapa foram realizadas as seguintes atividades ${ }^{5}$ :

a) entrevista não estruturada com profissional ligado a empresa de segurança privada;

b) entrevista semi-estruturada com membro do poder público legislativo municipal, o qual já foi Diretor do complexo prisional de Joinville/SC; 
c) entrevistas semi-estruturadas com três integrantes da equipe do projeto;

d) encontro com três participantes do projeto $^{6}$;

e) questionário enviado a duas integrantes da equipe de professores do projeto.

\section{Aplicação de ferramentas do design}

Foram utilizadas ferramentas do design nas interações do estudo de campo, no estabelecimento de diretrizes para a formação de parcerias e no desenvolvimento de plano estratégico com prospecção de parceiros. São elas:
a) Brainstorming;
b) Mapa de Agentes (stakeholders);
c) Visual thinking;
d) Diagrama de afinidades.

\section{Desenvolvimento de plano estratégico para prospecção de parceiros}

O plano estratégico desenvolvido para o projeto está baseado na metodologia Balanced Scorecard (BSC) proposta por Robert Kaplan e David Norton (RAMOS, 2018, web). O BSC é voltado ao gerenciamento de estratégias de empresas e está amplamente difundido no segundo setor. Para os objetivos deste trabalho, o BSC foi adaptado à realidade do Projeto CosturaViva, conforme Quadro 1.

Quadro 1 - Adaptação do Balanced Scorecard (BSC) para o Projeto CosturaViva

\begin{tabular}{|l|l|l|}
\hline \multirow{2}{*}{ Perspectivas BSC } & \multicolumn{2}{|c|}{ Projeto CosturaViva } \\
\cline { 2 - 3 } & Perspectivas & \multicolumn{1}{c|}{ Descrição } \\
\hline Financeira & Financeira & $\begin{array}{l}\text { Relativa aos recursos financeiros necessários ao } \\
\text { desenvolvimento do projeto (fontes e captação de } \\
\text { recursos) }\end{array}$ \\
\hline Clientes & Comercialização & $\begin{array}{l}\text { Diz respeito aos itens produzidos/serviços } \\
\text { oferecidos pelas participantes, e aos locais para } \\
\text { comercializá-los }\end{array}$ \\
\hline
\end{tabular}




\begin{tabular}{|l|l|l|}
\hline Processos Internos & Processos Internos & $\begin{array}{l}\text { Refere-se à melhoria e implantação de processos } \\
\text { internos (operacionais, inovação, etc.) que } \\
\text { contribuam para o atingimento dos objetivos do } \\
\text { projeto }\end{array}$ \\
\hline $\begin{array}{l}\text { Aprendizado e } \\
\text { Crescimento }\end{array}$ & Pessoas & $\begin{array}{l}\text { Relacionada aos agentes envolvidos, notadamente o } \\
\text { público-alvo do projeto }\end{array}$ \\
\hline
\end{tabular}

Fonte: Autoria própria (2020).

A intenção ao se utilizar este modelo foi a de proporcionar mais visibilidade às dimensões (perspectivas) envolvidas na formação de parcerias, propondo objetivos estratégicos e macroações para atingi-los.

\section{RESULTADOS E DISCUSSÃO}

A partir da aplicação da metodologia apresentada anteriormente, foram produzidos o mapa de agentes do projeto, as diretrizes para formação de parcerias e o plano estratégico com as parcerias prospectadas.

\section{Mapa dos agentes do projeto}

A ferramenta Mapa de Agentes foi utilizada para representar os entes envolvidos no projeto, a partir de uma visão sistêmica. Identificar os agentes propicia uma melhor compreensão do contexto, traz mais clareza acerca das relações e vínculos com diferentes grupos/organizações/setores, permite avaliar a influência e impacto dos envolvidos e possibilita encontrar oportunidades de parceria.

A identificação dos agentes do Projeto CosturaViva foi realizada com base no estudo do Projeto Integrado e do material escolhido para o aprofundamento teórico, pelas interações com a equipe e com as participantes do projeto, por meio de pesquisas na internet e com o brainstorming.

A Figura 1 apresenta o mapa do CosturaViva, com os agentes distribuídos nos grupos "Público-Alvo e Equipe", "Agentes Diretos" e "Agentes Indiretos". Como Agentes Diretos foram considerados aqueles críticos para o projeto funcionar, já os Indiretos são todos aqueles relacionados ao projeto, mas que não têm influência direta sobre a operação. 
Figura 1 - Mapa de Agentes do Projeto CosturaViva

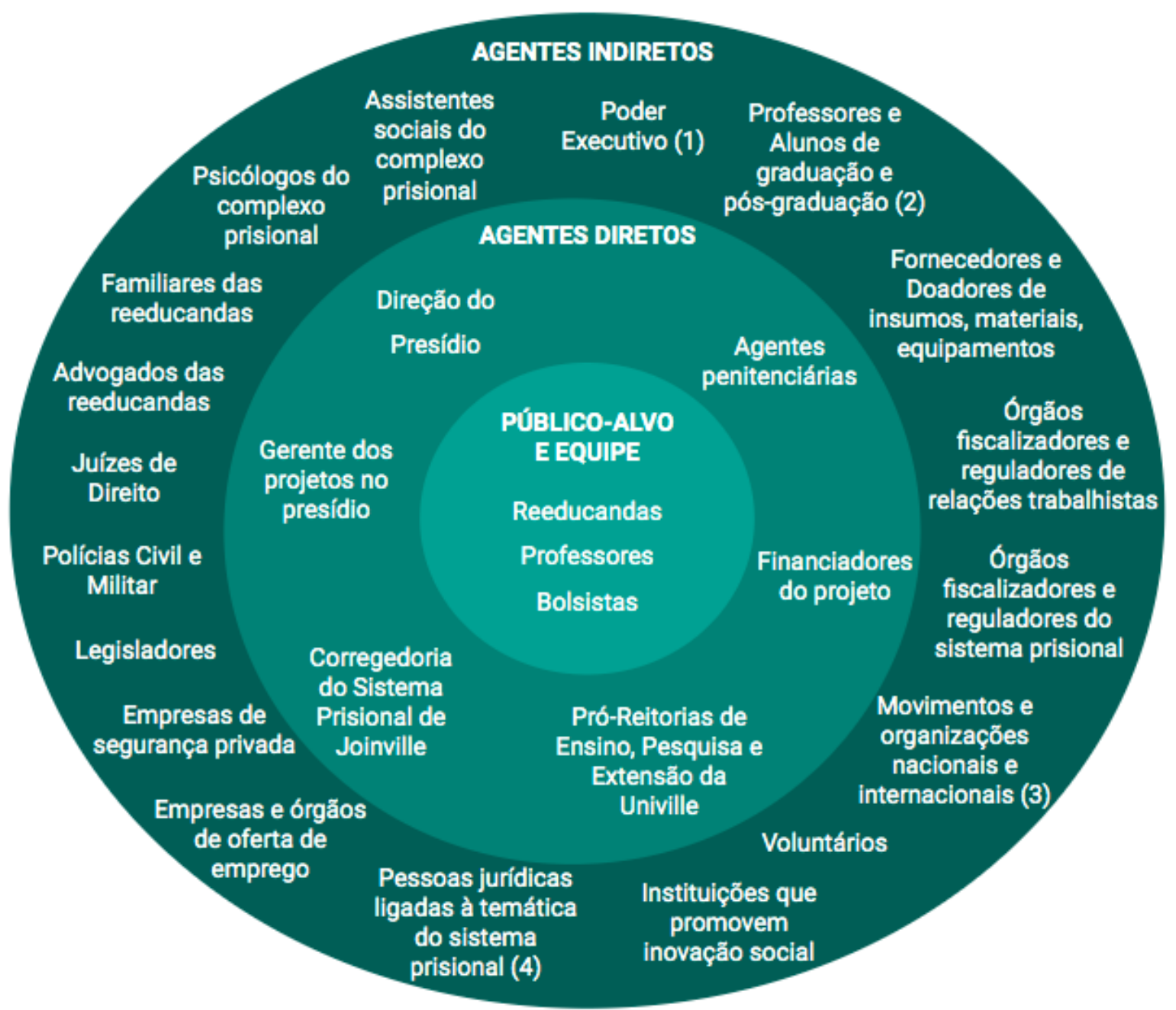

Fonte: Autoria própria (2020).

No Quadro 2 estão detalhados os agentes que, no mapa, aparecem de maneira genérica e acompanhados dos números de 1 a 4 .

Quadro 2 - Detalhamento do Mapa de Agentes do Projeto CosturaViva

\begin{tabular}{|l|l|l|}
\hline $\mathbf{N}^{\mathbf{0}}$ & Agente & Detalhamento \\
\hline 1 & Poder Executivo & - Poder executivo municipal, Secretaria Municipal de \\
& & Assistência Social e secretarias afins ao sistema prisional; \\
& & - Poder executivo estadual e secretarias afins ao sistema \\
& prisional; \\
& & - Poder executivo federal, com seus Ministérios e demais \\
& estruturas afins à temática do sistema prisional, como Ministério \\
& da Justiça e Segurança Pública, Ministério da Cidadania, \\
& Ministério do Desenvolvimento Regional, Ministério da Mulher, \\
& da Família e dos Direitos Humanos, Ministério da \\
& Economia/Instituto Nacional do Seguro Social (em função do \\
& Auxílio-Reclusão) e outros Ministérios relacionados à temática. \\
\hline
\end{tabular}




\begin{tabular}{|c|c|c|}
\hline 2 & $\begin{array}{l}\text { Professores e alunos } \\
\text { de graduação e pós- } \\
\text { graduação }\end{array}$ & $\begin{array}{l}\text { - Cursos de Administração, Design e Publicidade e Propaganda } \\
\text { da Univille; } \\
\text { - Cursos em áreas afins ao sistema prisional, como Direito, } \\
\text { Psicologia, Medicina, Serviço Social, Ciências Sociais, entre } \\
\text { outros, oferecidos pela Univille e outras instituições de } \\
\text { Joinville/SC. }\end{array}$ \\
\hline 3 & $\begin{array}{l}\text { Movimentos e } \\
\text { organizações } \\
\text { nacionais e } \\
\text { internacionais }\end{array}$ & $\begin{array}{l}\text { - Organizações de defesa dos direitos humanos/Conselhos de } \\
\text { Direitos Humanos; } \\
\text { - Organismos nacionais e internacionais, como a Prison } \\
\text { Fellowship International - PFI, organização consultora da ONU } \\
\text { para assuntos penitenciários; } \\
\text { - Organizações não governamentais (ONGs) que realizam } \\
\text { projetos/programas junto a reeducandos, egressos, familiares e } \\
\text { profissionais do sistema prisional; } \\
\text { - Organizações que desenvolvem ações de inserção e integração } \\
\text { de reeducandos, egressos e familiares ao mundo do trabalho; } \\
\text { - Instituições/organizações que atuam com temáticas afins, como } \\
\text { pessoas em situação de vulnerabilidade social e emocional, } \\
\text { geração de trabalho e renda, educação de adultos, coletivos } \\
\text { produtivos, infraestrutura/reformas, e empreendedores/negócios } \\
\text { de impacto social. }\end{array}$ \\
\hline 4 & $\begin{array}{l}\text { Pessoas jurídicas } \\
\text { ligadas à temática do } \\
\text { sistema prisional }\end{array}$ & $\begin{array}{l}\text { - Pessoas jurídicas financiadoras de projetos/programas } \\
\text { desenvolvidos junto a reeducandos, egressos, familiares e } \\
\text { profissionais do sistema prisional; } \\
\text { - Empresas/ONGs/Negócios de Impacto Social/Cooperativas que } \\
\text { ofertam vagas de trabalho na prisão para reeducandos, as que } \\
\text { empregam reeducandos do regime semiaberto e em liberdade } \\
\text { condicional e as que empregam egressos; } \\
\text { - Empresas/ONGs/Negócios de Impacto Social/Cooperativas/ } \\
\text { Redes de comércio justo e solidário que comercializam ou podem } \\
\text { vir a comercializar os produtos confeccionados pelos } \\
\text { reeducandos, egressos e familiares. }\end{array}$ \\
\hline
\end{tabular}

Fonte: Autoria própria (2020).

\section{Diretrizes para a formação de parcerias}

Tendo como subsídio os materiais consultados e as interações com os agentes, formulouse as seguintes diretrizes, que nortearam as indicações de parcerias no plano estratégico e podem balizar a efetivação das mesmas:

I. Os resultados da instrumentalização das reeducandas no campo do design de moda devem ser potencializados por meio de ferramentas de gestão e empreendedorismo, buscando-se sustentabilidade e autonomia;

II. O atendimento a questões ambientais é pauta obrigatória nas produções, priorizando-se o reaproveitamento de refugos da indústria de confecção, as matérias-primas naturais 
renováveis e as tintas naturais para estamparia;

III. Os projetos de produto são constituídos a partir do cruzamento entre saberes acadêmicos e conhecimentos próprios do grupo de mulheres participantes, instituindo-se uma identidade para o grupo produtor e promovendo-se a integração entre teoria e prática;

IV. A ressocialização das reeducandas tem como pressuposto a observância de aspectos relacionados ao estímulo à criatividade, à elevação da autoestima, à convivência harmoniosa e à oportunidade de inclusão e pertencimento ao grupo;

V. A solução de demandas socioculturais complexas, como é o caso da problemática do sistema prisional, passa pela reflexão coletiva em busca de possibilidades. Assim, a participação das reeducandas nas criações, produções e decisões é fundamental para o êxito da ressocialização;

VI. Para que o sistema prisional seja um mecanismo reintegrador efetivo, as atividades realizadas devem possuir a máxima similaridade com a sociedade externa;

VII. As parcerias devem estar pautadas em princípios legais e éticos, observando-se o ordenamento jurídico aplicável e os preceitos de integridade, ética e conduta definidos pela Universidade da Região de Joinville - Univille e pela FURJ - Fundação Educacional da Região de Joinville, bem como suas políticas e diretrizes com relação a parcerias, convênios, acordos e congêneres.

\section{Parcerias prospectadas}

Este item apresenta parceiros prospectados dentro da estrutura adaptada do BSC, conforme mencionado no tópico Metodologia.

As informações são exibidas conforme explicitado na Figura 2. 
Figura 2 - Estrutura de apresentação das parceiras prospectadas para o Projeto CosturaViva

\begin{tabular}{|c|c|c|c|}
\hline Perspectivas & $\begin{array}{c}\text { Objetivos } \\
\text { Estratégicos (OE) }\end{array}$ & Macroaçōes (M) & $\begin{array}{c}\text { Parcerias } \\
\text { Prospectadas }\end{array}$ \\
\hline $\begin{array}{l}\text { Dimensões estratégicas } \\
\text { do Projeto CosturaViva, } \\
\text { adaptadas do modelo } \\
\text { BSC: } \\
\text { - Financeira } \\
\text { - Comercialização } \\
\text { - Processos Internos } \\
\text { - Pessoas }\end{array}$ & $\begin{array}{l}\text { Foco estratégico dos } \\
\text { esforços a fim de se } \\
\text { atingir os objetivos do } \\
\text { Projeto CosturaViva. }\end{array}$ & $\begin{array}{l}\text { Conjuntos de atividades } \\
\text { relevantes para o } \\
\text { atingimento dos } \\
\text { objetivos estratégicos. } \\
\text { As macroações podem } \\
\text { ser desdobradas em } \\
\text { planos de ação (modelo } \\
5 W 2 \mathrm{H} \text {, por exemplo). }\end{array}$ & $\begin{array}{l}\text { Agentes com potencial } \\
\text { de contribuir para a } \\
\text { realização das } \\
\text { macroações e para o } \\
\text { atingimento dos } \\
\text { objetivos estratégicos. }\end{array}$ \\
\hline
\end{tabular}

Fonte: Autoria própria (2020).

A partir dos materiais consultados, das diretrizes formuladas e das demandas identificadas nas interações com os agentes, foi construído um plano estratégico para o Projeto CosturaViva, apresentado na sequência em suas Perspectivas Financeira (Figura 3), Comercialização (Figura 4), Processos Internos (Figura 5) e Pessoas (Figura 6).

Figura 3 - Projeto CosturaViva - Parcerias prospectadas na Perspectiva Financeira

\section{PERSPECTIVA FINANCEIRA}

Objetivos Estratégicos
Macroações

Parcerias Prospectadas
OE 1: Criar novas fontes de recursos para custeio do transporte da equipe, aquisição de insumos, equipamentos e mobiliário
M1.1: Apresentar o projeto para empresas de Joinville (recursos de Investimento Social Privado e ações de Responsabilidade Socioambiental Empresarial, como apoio financeiro a projetos e doações de insumos e equipamentos)

M1.2: Participar de editais públicos e privados de financiamento de projetos

M1.3: Registrar o projeto em plataformas de captação de recursos

\section{CosturaVivas:}

Tupy, Tigre, Docol, Whirlpool, Ciser, Amanco, Döhler, Clamed Farmácias, Mexichem Brasil, Schulz, Scherer, Krona, Multilog, Neogrid, Embraco Comitê RSA Univille

\section{Prosas}

ABCR - Associação Brasileira de Captadores de Recursos BrazilFoundation Abrace uma Causa 

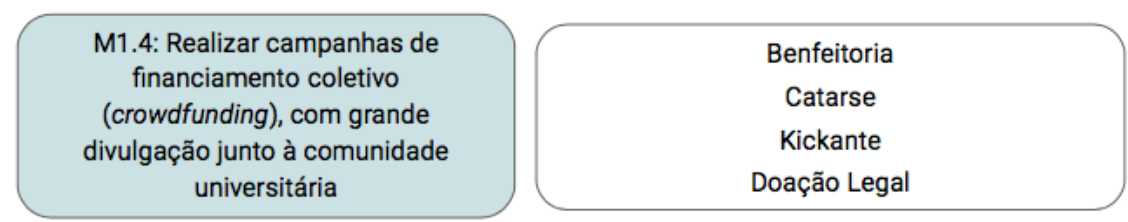

M1.5: Estudar as possibilidades de acesso a recursos do Poder Judiciário, como prestação pecuniária (a), Fundo Penitenciário Nacional (FUNPEN), Fundo Penitenciário da unidade prisional de Joinville e Procap - Programa de Capacitação Permanente (b)

Poder Judiciário local

Fonte: Autoria própria (2020).

O Quadro 3 apresenta informações adicionais acerca dos elementos da Perspectiva Financeira acompanhados pelas letras 'a' e 'b' no conteúdo da Figura 3.

Quadro 3 - Informações adicionais da Perspectiva Financeira

\begin{tabular}{|l|l|l|}
\hline Letra & Elemento & Informações adicionais \\
\hline a & $\begin{array}{l}\text { Prestação } \\
\text { Pecuniária }\end{array}$ & $\begin{array}{l}\text { Pagamento de um valor em dinheiro à vítima do crime, seus } \\
\text { dependentes, ou a uma instituição pública ou privada que vá destinar } \\
\text { esse valor ao uso social. Os detalhes são definidos pelo juiz, e o valor } \\
\text { pode variar de 1 a 360 salários mínimos (AGUIAR, 2017, web). }\end{array}$ \\
\hline b & Procap & $\begin{array}{l}\text { Programa de Capacitação Profissional e Implementação de Oficinas } \\
\text { Permanentes, no âmbito do Departamento Penitenciário Nacional, } \\
\text { vinculado ao Ministério da Justiça e Segurança Pública (BRASIL, } \\
\text { 2020b, web). }\end{array}$ \\
\hline
\end{tabular}

Fonte: Autoria própria (2020).

Figura 4 - Projeto CosturaViva - Parcerias prospectadas na Perspectiva Comercialização

PERSPECTIVA COMERCIALIZAÇÃO

\section{Objetivos Estratégicos}

OE 2: Definir itens a

serem produzidos e serviços oferecidos (a)

\section{Macroações}

Costuravivas:

\begin{tabular}{|c|c|c|}
\hline \multirow{2}{*}{$\begin{array}{l}\text { OE 2: Definir itens a } \\
\text { serem produzidos e } \\
\text { serviços oferecidos (a) }\end{array}$} & \multirow{2}{*}{$\begin{array}{l}\text { M2.1: Contatar empresas para } \\
\text { possível produção de brindes, } \\
\text { material promocional, uniformes e } \\
\text { itens utilizados na operação } \\
\text { M2.2: Contatar empresas/negócios } \\
\text { para realização de trabalhos e/ou } \\
\text { etapas do processo produtivo }\end{array}$} & $\begin{array}{c}\text { Univille, Negócios vinculados ao Inovaparq, } \\
\text { Escolas, Direção do complexo prisional, } \\
\text { Empresas que mantêm postos de trabalho } \\
\text { na penitenciária, Hoteis, Pousadas, } \\
\text { Restaurantes, Salões de beleza, estéticas e } \\
\text { barbearias, Empresas mapeadas na } \\
\text { Perspectiva Financeira }\end{array}$ \\
\hline & & $\begin{array}{l}\text { Subgrupos produtivos do Projeto AmaViva } \\
\text { (EcoBanner, Mútua, RedCarpet e Tiwa), } \\
\text { Marca Dente d'Leão, confecções em geral, } \\
\text { lojas de acessórios }\end{array}$ \\
\hline
\end{tabular}




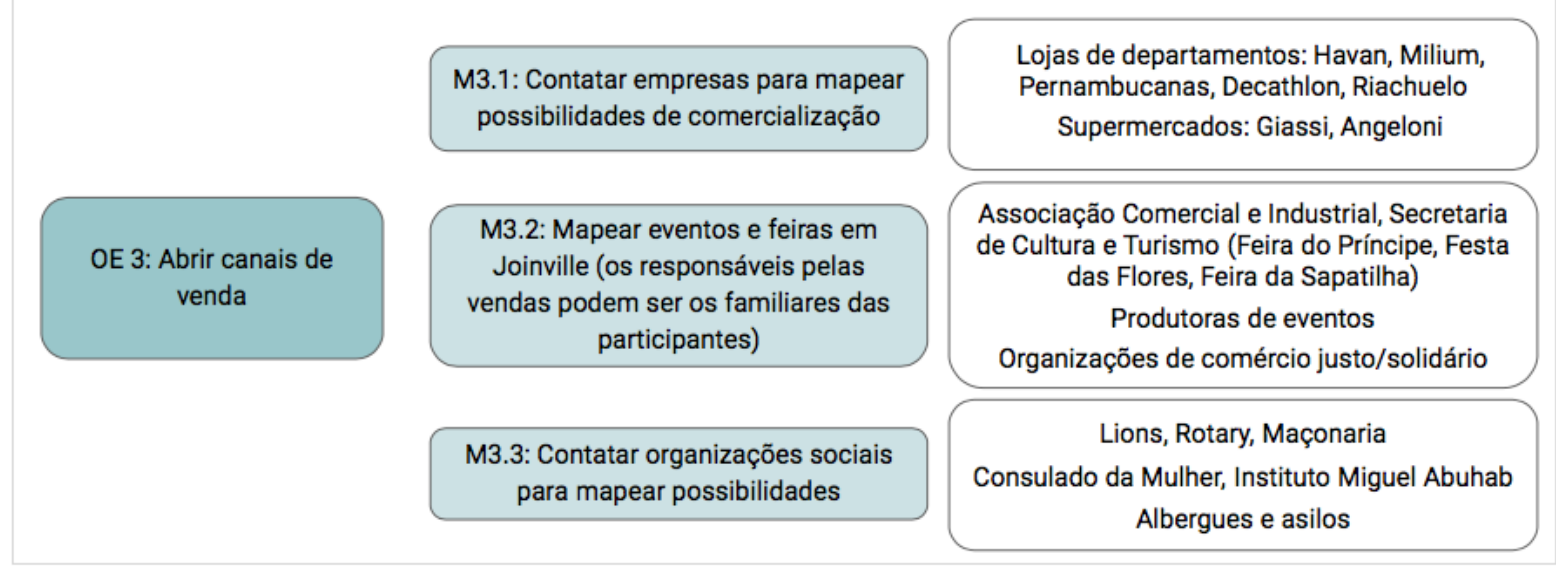

Fonte: Autoria própria (2020).

No sentido de contribuir com a definição dos itens para comercialização - objetivo estratégico acompanhado da letra 'a' no conteúdo da Figura 4 - a interação com os agentes e a realização de brainstorming resultaram na criação de um banco de ideias, conforme Quadro 4.

Quadro 4 - Produtos e serviços passíveis de comercialização pelo Projeto CosturaViva

\begin{tabular}{|l|l|}
\hline Item & Possibilidades \\
\hline Produtos & $\begin{array}{l}\text { Vestidos de tecido leve, moletom infantil, saia, tiara de bebê, acessórios para } \\
\text { criança, roupas femininas em geral, uniformes, peças para banheiro (toalhas, } \\
\text { tapetes), toalhas em geral (prato e mesa, inclusive para serem pintadas e bordadas } \\
\text { em outros projetos), lençois, fronhas, colchas, aventais, almofadas, bermudas, } \\
\text { camisetas, bonés, brindes sustentáveis (como ecobags, mochilas e estojos), toalhas } \\
\text { para atividade física, materiais para eventos (como sacolas, brindes e capas para } \\
\text { cadeiras), brindes e itens diversos para clubes de assinatura, produtos para pets } \\
\text { (caminhas, almofadas), lixeiras para carro, organizador veicular, "puxa-saco", } \\
\text { coletes para práticas esportivas, bolsas térmicas para alimentos, jogos americanos, } \\
\text { coberta para viagem que se transforma em travesseiro pequeno, fantasias para festas } \\
\text { e carnaval, lenços para pacientes em tratamento oncológico, itens para albergues e } \\
\text { asilos (toalhas, lençois, colchas). }\end{array}$ \\
\hline Serviços & $\begin{array}{l}\text { Ajustes em roupas doadas que seguirão para bazares, confecção de itens para kits } \\
\text { que são distribuídos a futuras mamães. }\end{array}$ \\
\hline
\end{tabular}

Fonte: Autoria própria (2020). 
Figura 5 - Projeto CosturaViva - Parcerias prospectadas na Perspectiva Processos Internos

\section{PERSPECTIVA PROCESSOS INTERNOS}

Macroações

\section{CostieraVivas}

Objetivos Estratégicos
M4.1: Organizar uma sala com bancadas, mesas e cadeiras adequadas ao processo (espaçosa, ventilada, iluminada, com mais estações de trabalho, acesso a banheiro e água potável)

OE 4: Melhorar a estrutura operacional (espaço, mobiliário, equipamentos), visando à produção seriada

M4.2: Adquirir máquinas (overloque, interloque, galoneira) e armário para guardar materiais
OE 5: Testar/Prototipar possibilidades de produção e comercialização
OE 6: Aprimorar o fluxo de informações do projeto
M4.3: Buscar indústrias de confecção para doarem insumos (como tecidos fora de linha), aviamentos e equipamentos

M5.1: Realizar benchmarking com projetos correlatos a fim de conhecer outras experiências relacionadas a processos e geração de renda

M5.2: Desenvolver projetos piloto/protótipos com algumas empresas para avaliar a viabilidade da parceria

M6.1: Estabelecer fluxo de comunicação com o presídio a fim de mitigar custos com transporte na ocorrência de cancelamento de aulas

M6.2: Desenvolver material de divulgação para apresentar aos possíveis parceiros

M6.3: Efetuar registro fotográfico das produções para montagem de portfólio das participantes

M6.4: Desenhar o fluxo do processo produtivo do projeto

M6.5: Registrar indicadores do projeto, a fim de demonstrar resultados aos possíveis parceiros (exemplos: pessoas impactadas, $n^{\circ}$ de oficinas, $n^{\circ}$ de horas de capacitação, $n^{\circ}$ de peças produzidas, nível de satisfação das participantes com o projeto) 
Figura 6 - Projeto CosturaViva - Parcerias prospectadas na Perspectiva Pessoas

PERSPECTIVA PESSOAS
Macroações

Parcerias Prospectadas

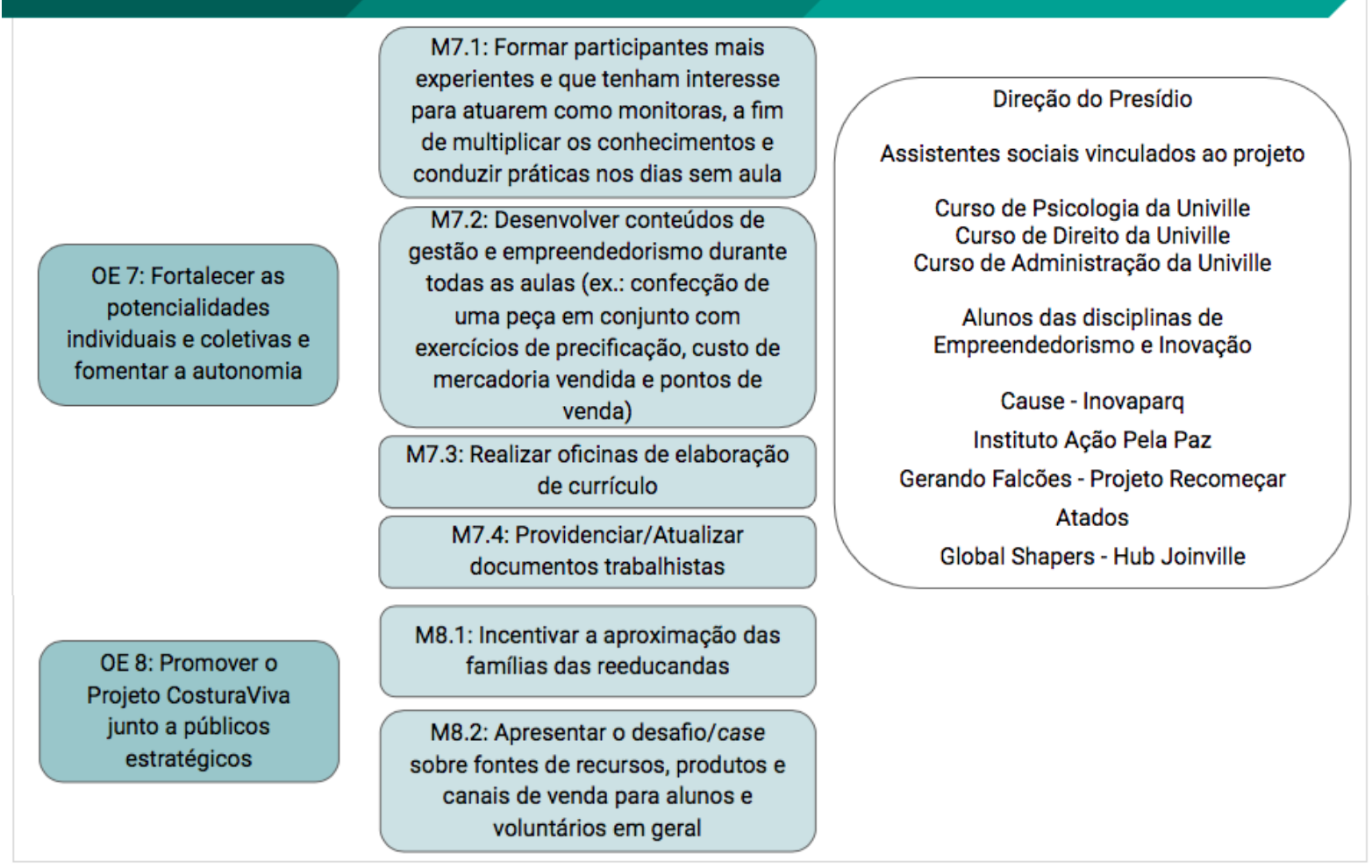

Fonte: Autoria própria (2020).

Considerando o plano estratégico apresentado, o percurso metodológico trilhado para a sua construção mostrou-se efetivo no seu objetivo de prospectar parcerias diversas. As possibilidades vislumbradas, se concretizadas, tendem a contribuir significativamente para a manutenção financeira do projeto e para a expansão do número de reeducandas participantes.

Dada a dinâmica inerente a qualquer projeto, é importante que os objetivos estratégicos sejam reavaliados periodicamente, a fim de confirmar sua pertinência e exequibilidade.

Além disso, é indicado que macroações sejam desdobradas em planos de ação e cronogramas de curto, médio e longo prazos, a partir dos entendimentos e priorizações da equipe do projeto em conjunto com as participantes e os agentes diretos.

Também é importante destacar que os objetivos estratégicos apresentados não esgotam a visão sistêmica do projeto, sendo indicado avançar em aspectos como estudo do público consumidor potencial, estratégias de branding, plano de marketing, logística, possibilidades de comercialização online, implantação de produção seriada vinculada a um único empregador, 
conexões profissionais para as egressas do sistema prisional, educação financeira e autoconhecimento com enfoque na dimensão profissional, entre outros.

\section{CONSIDERAÇÕES FINAIS}

Por meio deste relato de experiência foi compartilhado um modo de fazer que integra diversos saberes na construção de um plano estratégico para formação de parcerias junto ao Projeto CosturaViva.

Oferecendo subsídios metodológicos, o trabalho foi permeado pelo pragmatismo. Com este exercício de sistematização da jornada percorrida, espera-se que o processo apresentado possa ser facilmente adaptado e aplicado em outros projetos de extensão que se deparem com a mesma natureza de desafios.

Por fim, é significativo registrar a riqueza encontrada nas interações com as participantes do projeto. Não apenas riqueza de ideias, mas de espírito colaborativo, resiliência e potencial a ser desenvolvido, independente de estarem privadas de liberdade. A gratidão expressa nos olhos marejados mostrou que processos são importantes, mas o que vem com eles é mais importante ainda: sentir-se ouvida, acolhida, apreciada, respeitada.

\section{NOTAS}

1. Tal integração possibilita a realização de estágios e aplicação de pesquisas das graduações em Administração e Design e do Mestrado Profissional em Design.

2. Dentre os aspectos relevantes que dificultaram o desenvolvimento do projeto estão o espaço físico destinado às aulas, que não apresentava estrutura adequada, o baixo contingente de agentes penitenciárias para acompanhar as detentas até a sala, ocasionando cancelamento de aulas, e a interdição do presídio em junho/2019 (JOINVILLE, 2019, web), motivada por superlotação e não atendimento a requisitos de segurança contra incêndio e pânico.

3. Entende-se por prospecção a identificação e a qualificação de agentes com potencial para tornarem-se parceiros do projeto. 
4. O termo agentes refere-se ao conjunto de interessados - indivíduos, grupos e organizações - envolvidos na temática do sistema prisional.

5. Estavam previstos momentos de observação das atividades do grupo, os quais seriam realizados in loco, durante as aulas do projeto. Tais momentos não foram concretizados principalmente em função do início tardio das aulas em 2019, ocasionado pela interdição no presídio. Além disso, acontecimentos imprevistos demandaram as agentes penitenciárias que acompanhariam as participantes até o local das aulas, impossibilitando, mesmo com a equipe já presente no complexo prisional, a realização de um dos encontros em que haveria atividades relacionadas a este trabalho.

6. Também foi escopo deste encontro conhecer os anseios das participantes em relação ao projeto.

\section{REFERÊNCIAS}

AGUIAR, João Paulo de Vasconcelos. 5 Penas Alternativas à Prisão no Brasil. Publicado em 11 mai. 2017. Disponível em <https://www.politize.com.br/penas-alternativas-aprisao-no-brasil/>. Acesso em: $18 \mathrm{dez} 2019$.

BOURDIEU, Pierre. A economia das trocas simbólicas. São Paulo: Perspectiva, 2007. A Distinção: crítica social do julgamento. São Paulo: Edusp; Porto Alegre, RS: Zouk, 2008.

BRASIL. Ministério da Justiça e Segurança Pública. Departamento Penitenciário Nacional. Relatório de Execução Orçamentária FUNPEN 2019. Disponível em: 〈https://www.gov.br/depen/pt-br/RelatriodeExecuoOramentriaFUNPEN.pdf/view>. Acesso em: 07 jan. 2020a.

. Ministério da Justiça e Segurança Pública. Departamento Penitenciário Nacional. Trabalho e Renda. Disponível em: <https://www.gov.br/depen/pt-br/acesso-ainformacao/acoes-e-programas/trabalho-e-renda/trabalho-e-renda>. Acesso em: 07 jan. $2020 \mathrm{~b}$.

CAPRA, Fritjof, LUISI, Pier Luigi. A visão sistêmica da vida: uma concepção unificada e suas implicações filosóficas, políticas, sociais e econômicas. São Paulo: Cultrix, 2014. 
CIPINIUK, Alberto. Design: o livro dos porquês: o campo do Design compreendido como produção social. Rio de Janeiro: Ed. PUC-Rio; São Paulo: Ed. Reflexão, 2014.

FONTANA, Daiane Lais. Design e artesanato: plano de negócio para artefatos produzidos por projeto social. Relatório técnico (Mestrado em Design - Universidade da Região de Joinville). Joinville: UNIVILLE, 2018. Disponível em <https://www.univille.edu.br/account/ppgdesign/VirtualDisk.html/downloadDirect/1739812/ Daiane_Lais_Fontana.pdf $>$. Acesso em 17 jan. 2020.

GUIDO, Gilzia Dias Payão. Sistema Prisional e a Ressocialização do Preso. Trabalho de Conclusão de Curso (Graduação em Direito - Instituto Municipal de Ensino Superior de Assis - IMESA e Fundação Educacional do Município de Assis - FEMA). Assis, 2015. Disponível em <https://cepein.femanet.com.br/BDigital/arqTccs/1211400211.pdf>. Acesso em 05 jun. 2019.

JOINVILLE. Câmara de Vereadores. Comissão especial vai analisar superlotação do Presídio Regional. Publicado em 06 jun. 2019. Disponível em <http://www.cvj.sc.gov.br/home/47-comissoes/4907-comissao-especial-vai-analisarsuperlotacao-do-presidio-regional>. Acesso em 20 jan. 2020.

MORGENSTERN, Elenir (org.); HERMES, Leticia (org.); AGUIAR, Victor (org.). Design e capacitação profissional: práticas associadas integrando ensino, pesquisa e extensão. Joinville, SC: Editora Univille, 2018. Disponível em <https://www.univille.edu.br/account/editora/VirtualDisk.html/downloadDirect/1428244/>. Acesso em 20 jan. 2020.

RAMOS, Davidson. O que é BSC (Balanced Scorecard). Publicado em 06 mar. 2018. Disponível em: 〈https://blogdaqualidade.com.br/o-que-e-bsc-balanced-scorecard/>. Acesso em: 28 nov. 2019.

SANTA CATARINA. Secretaria de Estado da Administração Prisional e Socioeducativa. Projeto da SAP irá instalar 13 novas oficinas de capacitação em unidades prisionais. $\begin{array}{llllll}\text { Publicado em } & 16 & \text { dez. } & 2019 . & \text { Disponível }\end{array}$ $<$ http://www.sap.sc.gov.br/index.php/noticias/todas-as-noticias/8943-projeto-da-sap-i $\quad \mathrm{r} \quad \mathrm{a}-$ instalar-13-novas-oficinas-de-capacitacao-em-unidades-prisionais>. Acesso em 10 jan. 2020. 
_. Secretaria de Estado da Administração Prisional e Socioeducativa. Todas as Notícias. Disponível em <http://www.sap.sc.gov.br/index.php/noticias/todas-as-noticias>. Acesso em 07 jan. 2020.

SILVA, Jéssica de Almenau da. Indústria de moda e projetos sociais: possíveis práticas de cooperação. Dissertação (Mestrado em Design - Universidade da Região de Joinville). Joinville: UNIVILLE, 2016. Disponível em <https://www.univille.edu.br/account/ppgdesign/VirtualDisk.html/downloadDirect/949603/Je ssica_de_Almenau_da_Silva.pdf>. Acesso em 15 jan. 2020.

SILVA, Samantha Pereira da; KANAMARU, Antônio Takao. Design social e sistema carcerário: novas atuações do mercado de moda. CINM - Congresso Internacional de Negócios da Moda, 5 $5^{\mathrm{a}}$ ed., São Paulo, 2017. Disponível em <http://cinm.org.br/cinm/anais/2017/01_01_03_Design social e sistema carcerário.pdf>. Acesso em 07 jul. 2019.

STEINER, Ricardo. Desenvolvimento de brinde a partir do reuso de materiais: uma perspectiva sustentável. Dissertação (Mestrado em Design - Universidade da Região de Joinville). Joinville: UNIVILLE, 2016. Disponível em <https://www.univille.edu.br/account/ppgdesign/VirtualDisk.html/downloadDirect/944801/Ri cardo_Steiner.pdf>. Acesso em 15 jan. 2020.

WOLFF, Janet. A Produção Social da Arte. Zahar Editores, 1982.

Endereços eletrônicos para consulta às parcerias prospectadas:

ABCR - Associação Brasileira de Captadores de Recursos: <https://captadores.org.br/category/c40-editais-abertos/>

Abrace uma Causa: 〈https://abraceumacausa.com.br>

ANIP - Articuladora de Negócios de Impacto na Periferia: <https://www.articuladoranip.com>

Atados - Voluntariado: 〈https://www.atados.com.br>

Benfeitoria: 〈https://benfeitoria.com>

BrazilFoundation: 〈https://brazilfoundation.org/?lang=pt-br> 
Catarse: 〈https://www.catarse.me>

Cause - Inovaparq: 〈https://inovaparq.com.br/cause/>

Consulado da Mulher: <http://consuladodamulher.org.br>

Coopa-Roca: 〈https://www.coopa-roca.com.br>

Doação Legal: 〈https://doacaolegal.com.br>

Feira Preta: 〈http://feirapreta.com.br>

Gerando Falcões - Projeto Recomeçar: 〈https://gerandofalcoes.com/recomecar〉

Global Shapers - Hub Joinville: 〈https://www.globalshapers.org/hubs/joinville-hub >

Instituto Ação Pela Paz: 〈https://acaopelapaz.org.br>

Kickante: 〈https://www.kickante.com.br>

Marca Dente d'Leão: 〈http://dentedleao.com.br>

Pano Social: 〈http://panosocial.com.br>

Prosas: <https://prosas.com.br $\geq$

Recebido em: 05 de julho de 2020.

Aceito em: 11 de novembro de 2020. 
